\title{
Laterite Based Stabilized Products for Sustainable Building Applications in Tropical Countries: Review and Prospects for the Case of Cameroon
}

\author{
Patrick N. Lemougna, Uphie F. Chinje Melo, Elie Kamseu* and Arlin B. Tchamba \\ Local Materials Promotion Authority, MINRESI/MIPROMALO, P.O. Box 2396, Yaounde, \\ Nkolbikok 1, Cameroon; E-Mails: lemougna@yahoo.fr (P.N.L.); chinjeuphie@yahoo.co.uk \\ (U.F.C.M.); attchamba@yahoo.fr (A.B.T.) \\ * Author to whom correspondence should be addressed; E-Mail: kamseuelie2001@ yahoo.fr; \\ Tel.: +237-22-22-37-20; Fax: +237-22-22-37-20.
}

Received: 19 December 2010 / Accepted: 18 January 2011 / Published: 19 January 2011

\begin{abstract}
Lateritic soils are formed in the tropics through weathering processes that favor the formation of iron, aluminum, manganese and titanium oxides. These processes break down silicate minerals into clay minerals such as kaolinite and illite. Iron and aluminum oxides are prominent in lateritic soils, and with the seasonal fluctuation of the water table, these oxides result in the reddish-brown color that is seen in lateritic soils. These soils have served for a long time as major and sub-base materials for the construction of most highways and walls of residential houses in tropical and sub-tropical countries of the world. Civil engineering applications of these lateritic soils are continually being developed with the use of different types of stabilizers. The stabilized soil-based products are as such viewed as environmentally-friendly and low-cost energy materials for sustainable building applications. This work aims at presenting a global view of what has been done in the field of lateritic soil improvement for construction purposes in tropical countries such as Cameroon. This shall be discussed through the presentation of the structure, composition and properties of lateritic soils, the various ways of improving their properties for construction purposes, the properties of products obtained and other prospects.
\end{abstract}

Keywords: tropical countries; lateritic soils; construction; properties; environmentally-friendly 


\section{Introduction}

The term Laterite is derived from the Latin word "later", meaning brick. It was first used in 1807 by Buchanan to describe a red iron-rich material found in the southern parts of India. Laterites are widely distributed throughout the world in the regions with high rainfall, but especially in the inter-tropical regions of Africa, Australia, India, South-East Asia and South America, where they generally occur just below the surface of grasslands or forest clearings. Their extension indicates that conditions were favorable for their formation at some point in time in the history of the world, but not necessarily simultaneously in all regions [1].

Laterites contribute to the general economy of the regions where they are found. Their scope is very wide and includes civil engineering, agronomic, mining research (iron, aluminum and manganese) deposits. There is no need to emphasize the importance of laterites for various building purposes. Laterite crusts were originally widely used for the construction of monuments and dwellings. Certain African megaliths like "Tazunu", located in the northwest of the Central African Republic, are of lateritic origin, in addition to rock minerals [1,2]. The use of indurated laterites as a building material has been, and is still very common in Africa [1,3]. Civil engineering studies of these materials are now in progress, with focus on their use in road and earth dam construction [1].

One of the main uses of laterites for construction purposes is the production of Compressed Earth Blocks (CEB). The production technology for CEB provides a modern use of lateritic soils for walls and meets the building requirements for structural performance. In addition, a high esthetic quality of buildings can be achieved. The technical development of CEB use in Cameroon dates back to the 1980s, when a training program on the use of this technology was initiated and Terstaram presses were acquired with the support and collaboration of foreign expertise (the "Centre International de la Construction en Terre" (Craterre-EAG), United Nations Development Programme (UNDP), United Nations Industrial Development Organization (UNIDO), as well as private promoters). Many buildings constructed under this program and through the Locals Materials Promotion Authority (MIPROMALO) activities still exist with satisfactory results, showing that the use of CEB is an ideal way to promote low-cost and environmentally friendly housing.

Ever since, the technology of CEB production and its use in construction have steadily increased both scientifically and technically, thus providing evidence of its value. Simultaneously, the Cameroon government has made contributions for its social and economic development. Cameroonian standards for CEB (a set of 14 standards defining terminology, dimensions, raw material testing method, products testing methods, minimal requirement for mortar and CEB, as well as good practice code for production and construction) was established in 2006 and the Prime Minister, the Head of Government in 2007, signed a circular instructing the construction of public buildings (up to one level) with local materials (including CEB). However all these efforts need to be kept and to be improved on both scientifically and through popularization.

This paper reviews the research that has been carried out on the improvement of lateritic soils for construction reasons, with the aim of promoting this technology. Emphasis has been laid on the products' quality and environmentally friendly processes in order to promote the development of sustainable and environmentally favorable building policies. 


\section{Structure, Composition and Properties of Lateritic Soils}

Laterites vary greatly in structure, but can be reduced to the following three structural patterns:

(a) The indurated elements form a continuous, coherent skeleton;

(b) The indurated elements are free concretions or nodules in an earthy matrix;

(c) The indurated elements cement pre-existing materials.

These structural patterns exhibit great variability in relation to the shape and size of the elements involved and the degree of induration. The degree of hardness ranges from products that are practically unconsolidated and scarcely coherent to the hardest blocks which can be broken only with a hammer. Induration is an empirical criterion, as it is impossible to give quantitative expressions to any character related to the mechanical properties of the material. The usual definition of induration is a state in which the hard brittle consistency of the medium is not affected by humidity. Induration, which involves the precipitation of goethite in a reticular network, is influenced by composition and the extent of crystallization of the components in the soil: the higher the sesquioxide content, the greater the induration. In other words, hardness increases as the iron content increases; the hardest laterites are also the least hydrated $[1,4]$.

Laterites vary in color, but are usually brightly colored. The shades most frequently encountered are pink, ochre, red and brown; however, some occurrences are mottled and streaked with violet, and others exhibit green marbling. A single sample may exhibit a whole range of colors merging more or less perceptibly into one another in a variety of patterns and forms. Laterites owe their color to iron oxides in various states of hydration and sometimes also to manganese [1]. Their mineralogy generally involves quartz, kaolinite, hematite, goethite [3,5,6], and sometime maghemite. Kaolinite is always present with iron oxides.

The physical properties of lateritic soil vary according to the mineralogical composition and particle size distribution of the soil. The granulometry can vary from very fine to gravel according to its origin, thus influencing geotechnical properties such as plasticity and compressive strength. One of the main advantages of lateritic material is that it does not readily swell with water. This makes it an excellent packing material particularly when it is not too sandy [1].

\section{Improving Lateritic Soils for Construction Purposes}

Stabilization processes are very complex because many parameters come into play. The knowledge of soil properties can help to better consider what changes, the economic studies (cost and time), as well as production and construction techniques to use. The simplest process consists of taking soil and drying it in open-air. It is the "pise" technique, rammed earth, adobe, and brick dried in the sun, widely used in the majority of African countries. More elaborate processes can include heat treatment, or mixing soil with ordinary Portland cement, lime, etc.

The principles of some of these stabilization processes are described below. 


\subsection{Mechanical Stabilization}

Mechanical stabilization consists of compacting the soil to affect its resistance, compressibility, permeability and porosity. The soil is mechanically treated so that maximum air can be eliminated and this contributes to an increase in its density. With mechanical stabilization, the particle size distribution constituting the material is not affected, but its structure is changed because the particles are redistributed $[7,8]$. Mechanical stabilization is widely used in road construction and requires a prior analysis of the soil to determine the optimum water content for better soil compressibility.

\subsection{Physical Stabilization}

Physical stabilization consists of modifying the properties of soil by intervening with its texture (granulometry treatment, heat (dehydration or freezing) or electric (electrosmosis) treatments that lead to the drainage of the soil and thus confer new structural properties to it) [7,8]. Physical stabilization may also involve the introduction of synthetic fibers or fibers originating from plants, animals and minerals into the soil. This method is used when there are reasons not to affect the particle size distribution of the soil or if the material is sensitive to movements induced by factors such as water action, thermal expansion, etc. These movements can then be countered by a frame made of fibers. The armature acts at a macroscopic level (on grain aggregation), and not at the level of individual grains [7].

\subsection{Chemical Stabilization}

Chemical stabilization consists of adding other materials to the soil or chemicals that alter its properties, either by a physico-chemical reaction between particles and the added materials or by creating a matrix that binds or coats the particles. The physico-chemical reaction can cause the formation of a new material made from a pozzolanic reaction between clay and limestone, for example [7].The most often used additives for soil stabilization are cement, lime or a cement/lime mixture [9].

\subsubsection{Lime Stabilization}

When introducing lime into soil for stabilization, $\mathrm{Ca}^{2+}$ are partly adsorbed on the surfaces of clay particles in replacement of monovalent cations such as $\mathrm{Na}^{+}$and $\mathrm{K}^{+}$[9]. The amount of $\mathrm{Ca}^{2+}$ adsorbed depends on the cation exchange capacity of the treated soil. The more the exchange capacity, the higher the amount of $\mathrm{Ca}^{2+}$ absorbed by the soil. In fact, all the adsorbed cations are no longer available for pozzolanic reactions. The amount of lime required to satisfy the affinity of soil for lime is called the Lime Fixation Point (LFP). The lime in excess of the LFP is involved in the process of cementing. The reactions between the lime, silica and alumina-free, contributing to the formation of new minerals such as CSH (calcium silicate hydrates), CAH (calcium aluminate hydrates) and CASH (aluminocalcium silicate hydrates), are primarily responsible for the consolidation. These reactions are more or less slow and depend on various factors such as mineralogy, grain sizes of the treated soil, as well as curing time and temperature [9]. 


\subsubsection{Cement Stabilization}

The main reaction in a soil/cement mixture comes from the hydration of the two anhydrous calcium silicates $\left(3 \mathrm{CaO} . \mathrm{SiO}_{2}\left(\mathrm{C}_{3} \mathrm{~S}\right)\right.$ and $\left.2 \mathrm{CaO} . \mathrm{SiO}_{2}\left(\mathrm{C}_{2} \mathrm{~S}\right)\right)$, the major constituents of cement, which form two new compounds: calcium hydroxide (hydrated lime called portlandite) and calcium silicate hydrate (CSH), the main binder of concrete $[9,10]$. The reaction is as follows (Equation 1):

$$
\text { cement }+\mathrm{H}_{2} \mathrm{O} \rightarrow \mathrm{CSH}+\mathrm{Ca}(\mathrm{OH})_{2}
$$

Unlike lime, the mineralogy and granulometry of cement treated soils have little influence on the reaction since the cement powder contains in itself everything it needs to react and form cementitious products. Cement will create physical links between particles, increasing the soil strength; meanwhile lime needs silica and alumina from clay particles to develop pozzolanic reactions $[9,11]$.

Generally, the hydration reactions of cements are faster than those of lime, but in both cases, the final strength results from the formation of CSH [11]. Other chemical materials such as gypsum, asphalt and bitumen can be also used.

\subsection{Low Temperature Geopolymeric Setting (LTGS) Process}

The use of low temperature geopolymeric setting (LTGS) for the production of construction materials has been proven to be environmentally friendly (J. Davidovits, 1988). Nearly all clay soils containing minerals such as kaolinite, montmorionite, phyllite, muscovite, chlorite, etc., are capable of reacting with alkali (e.g., caustic soda) to form ceramic-like materials of type polysialate -Si-O-Al-Oor poly (sialate-siloxo) -Si-O-Al-O-Si-O- at temperatures between $50{ }^{\circ} \mathrm{C}$ and $500{ }^{\circ} \mathrm{C}$. The presence of clayey minerals, such as kaolinite, in lateritic soil is responsible for the potentiality that this type of soil possesses to reticulate. The equation for the reaction of kaolinite with $\mathrm{NaOH}$ at $100-150{ }^{\circ} \mathrm{C}$ is presented below [12]:

$$
\mathrm{Si}_{2} \mathrm{O}_{5}, \mathrm{Al}_{2}(\mathrm{OH})_{4}+2 \mathrm{NaOH} \longrightarrow\left(\mathrm{Si}_{2} \mathrm{O}_{4}, \mathrm{Al}_{2} \mathrm{O}_{4}, 2 \mathrm{Na}\right), 3 \mathrm{H}_{2} \mathrm{O}
$$

Kaolinite

Hydrosodalite Na-PCDS

Na-PCDS (sodium poly (cyclodisialate))is a tridimensional poly(aluminosilicate) stable to water having a strong mechanical resistance. Sialate is an abbreviated form of silicon-oxo-aluminate. The sialate network consists of $\mathrm{SiO}_{4}$ and $\mathrm{AlO}_{4}$ tetrahedra linked alternatively by all sharing the oxygen. Positive ions such as $\mathrm{Na}^{+}, \mathrm{K}^{+}, \mathrm{Ca}^{++}$, etc., provided by alkaline reagents, must be present in the framework cavities to balance the negative charge of $\mathrm{Al}$ in four-fold coordination. These ions act as catalysts enabling mineralogical components to react between them, to reticulate and to set. It is the argillaceous material itself that manufactures the binder for agglomeration in situ. The process is comparable to that which takes place during ceramic firing at $900-1100{ }^{\circ} \mathrm{C}$; the difference with LTGS being that the setting can start even at room temperature.

Alkaline reagents such as $\mathrm{NaOH}$ or $\mathrm{KOH}$ can be added up to $10 \mathrm{wt} \%$ of the soil mass depending on the type and amount of clays present in the soil [12-14]. 


\section{Engineering Properties and Applications}

Mbumbia et al. [6] studied the improvement of the physical and mechanical properties of some lateritic soil bricks after stabilization through heat with a view of assessing their suitability for the construction of walls for simple houses. Table 1 shows the engineering properties obtained after heat treatment.

Table 1. Physical and mechanical properties of specimens of fired lateritic soil bricks after heat treatment (adapted from [6]).

\begin{tabular}{|c|c|c|c|c|c|c|c|c|c|c|c|c|}
\hline \multirow{2}{*}{$\begin{array}{l}\text { Temperature of firing } \\
\left({ }^{\circ} \mathrm{C}\right) \\
\text { Dwell time of firing }(\mathrm{h})\end{array}$} & \multirow{2}{*}{$\begin{array}{l}27 \\
- \\
\end{array}$} & \multirow{2}{*}{$\begin{array}{r}110 \\
- \\
\end{array}$} & \multicolumn{2}{|c|}{350} & \multicolumn{2}{|c|}{550} & \multicolumn{2}{|c|}{750} & \multicolumn{2}{|c|}{850} & \multicolumn{2}{|c|}{975} \\
\hline & & & 4 & 8 & 4 & 8 & 4 & 8 & 4 & 8 & 4 & 8 \\
\hline \multicolumn{13}{|l|}{$\begin{array}{l}\text { Apparent dry density } \\
\left(\times 10^{3} \mathrm{Kg} / \mathrm{m}^{3}\right)\end{array}$} \\
\hline Minimum & 1.66 & 1.64 & 1.61 & 1.61 & 1.54 & 1.54 & 1.52 & 1.47 & 1.54 & 1.54 & 1.64 & 1.66 \\
\hline Maximum & 1.68 & 1.69 & 1.65 & 1.64 & 1.59 & 1.56 & 1.55 & 1.52 & 1.56 & 1.55 & 1.66 & 1.67 \\
\hline Average & 1.67 & 1.66 & 1.63 & 1.63 & 1.57 & 1.55 & 1.53 & 1.50 & 1.55 & 1.55 & 1.65 & 1.66 \\
\hline \multicolumn{13}{|l|}{ Volumic shrinkage (\%) } \\
\hline Minimum & - & - & 0 & 0 & 1 & 2 & 1 & 0 & 5 & 2 & 9 & 9 \\
\hline Maximum & - & - & 1 & 2 & 5 & 3 & 4 & 3 & 6 & 4 & 11 & 10 \\
\hline Average & - & - & 0.4 & 1.0 & 3.5 & 2.7 & 2.5 & 1.8 & 5.4 & 3.5 & 9.8 & 9.3 \\
\hline \multicolumn{13}{|l|}{ Water absorption (\%) } \\
\hline Minimum & - & - & 29.54 & 27.02 & 26.75 & 27.24 & 27.89 & 28.04 & 27.67 & 27.53 & 26.27 & 26.27 \\
\hline Maximum & - & - & 30.07 & 29.01 & 27.24 & 27.34 & 28.43 & 28.30 & 28.13 & 27.76 & 26.88 & 26.93 \\
\hline Average & - & - & 29.73 & 27.88 & 27.02 & 27.28 & 28.08 & 28.16 & 27.90 & 27.69 & 26.48 & 26.63 \\
\hline \multicolumn{13}{|l|}{$\begin{array}{l}\text { Modulus of rupture } \\
\left(\times 10^{6} \mathrm{~N} / \mathrm{m}^{2}\right)\end{array}$} \\
\hline Minimum & 0.96 & 1.42 & 1.47 & 1.43 & 0.94 & 0.88 & 0.86 & 0.92 & 1.11 & 1.30 & 1.42 & 1.53 \\
\hline Maximum & 1.06 & 1.54 & 1.51 & 1.62 & 1.20 & 1.03 & 0.88 & 0.97 & 1.19 & 1.34 & 1.70 & 1.62 \\
\hline Average & 1.00 & 1.47 & 1.50 & 1.51 & 1.05 & 0.96 & 0.87 & 0.94 & 1.14 & 1.32 & 1.59 & 1.58 \\
\hline \multicolumn{13}{|l|}{$\begin{array}{l}\text { Compressive strength } \\
\left(\times 10^{6} \mathrm{~N} / \mathrm{m}^{2}\right)\end{array}$} \\
\hline Minimum & 2.67 & 3.18 & 4.45 & 4.35 & 9.12 & 9.15 & 9.49 & 9.89 & 11.05 & 11.48 & 13.73 & 14.61 \\
\hline Maximum & 3.09 & 3.47 & 4.88 & 4.46 & 10.10 & 10.01 & 10.29 & 10.76 & 11.49 & 11.99 & 14.53 & 14.77 \\
\hline Average & 2.90 & 3.35 & 4.60 & 4.41 & 9.75 & 9.59 & 9.95 & 10.33 & 11.27 & 11.80 & 14.23 & 14.69 \\
\hline \multirow[t]{3}{*}{ Erodibility } & Disintegra & Disintegra & \multirow{3}{*}{\multicolumn{2}{|c|}{ Major cracks }} & \multirow{3}{*}{\multicolumn{2}{|c|}{ No effect }} & \multirow{3}{*}{\multicolumn{2}{|c|}{ No effect }} & \multirow{3}{*}{\multicolumn{2}{|c|}{ No effect }} & \multirow{3}{*}{\multicolumn{2}{|c|}{ No effect }} \\
\hline & -ted after & -ted after & & & & & & & & & & \\
\hline & $30 \mathrm{~min}$ & $2 \mathrm{~h}$ & & & & & & & & & & \\
\hline
\end{tabular}

Table 1 demonstrates that using this technique, it is possible to produce strong bricks at very low firing temperatures without any additives. Since most lateritic soils contain essential minerals such as quartz, kaolinite, iron oxides and hydroxides, the proposed route will be to reduce the particle size of raw materials to obtain medium and fine particles. The crushing of raw materials to a size near to powder will increase the proportion of fine particles and will therefore increase the specific contact surface of the particles, thus facilitating their fusion by diffusion bonding when they are heated to specific temperatures [6]. Notwithstanding the low values of rupture modulus and the relative high porosity of lateritic soil bricks, the high compressive strengths obtained are suitable for the level of 
loads carried by ordinary single-storey dwellings. For ordinary buildings with one floor, the loads are low and therefore the compressive strengths obtained are widely sufficient.

The aptitude of burnt clay-slaked lime (SL) binder to stabilize lateritic soil has been studied by Billong et al. [3]. The influences of different factors and relevant modalities (factor's levels) on the engineering properties of lateritic soil are presented in Figures 1-3. The factors investigated are the $\%$ SL in the binder, the ratios of water:solid, laterite:binder and $\mathrm{NaOH}$ :binder.

From the investigations carried out in this study [3], the following conclusions were made with regard to the effect of the mixture components on the properties of compressed lateritic soil stabilized with a lime-burnt clay binder:

- Increase of the percentage of lime in the binder increases compressive strength of the final product and slightly decreases water absorption and apparent density.

- Increase of the water-solid (laterite and binder) ratio shows a maximum compressive strength at a water:solid ratio of 0.16 . At this ratio, minimum water absorption and maximum apparent density are observed.

- The increase in the ratio of laterite:binder decreases the compressive strength, slightly reducing water absorption and increasing apparent density.

- The presence of sodium hydroxide $(\mathrm{NaOH})$ slightly increases compressive strength at $\mathrm{NaOH}$-binder ratios of less than 0.03 . In the same interval, water absorption is slightly decreased. The ratio of $\mathrm{NaOH}$ :binder has a great effect on the apparent density: it increases when the $\mathrm{NaOH}$ :binder ratio increases.

Figure 1. The average effect of factors (\% slaked lime in the binder, the ratios of burnt clay-SL binder. water:solid, laterite:binder and $\mathrm{NaOH}$ :binder) on compressive strength of lateritic soil with burnt clay-SL binder (adapted from [3]).

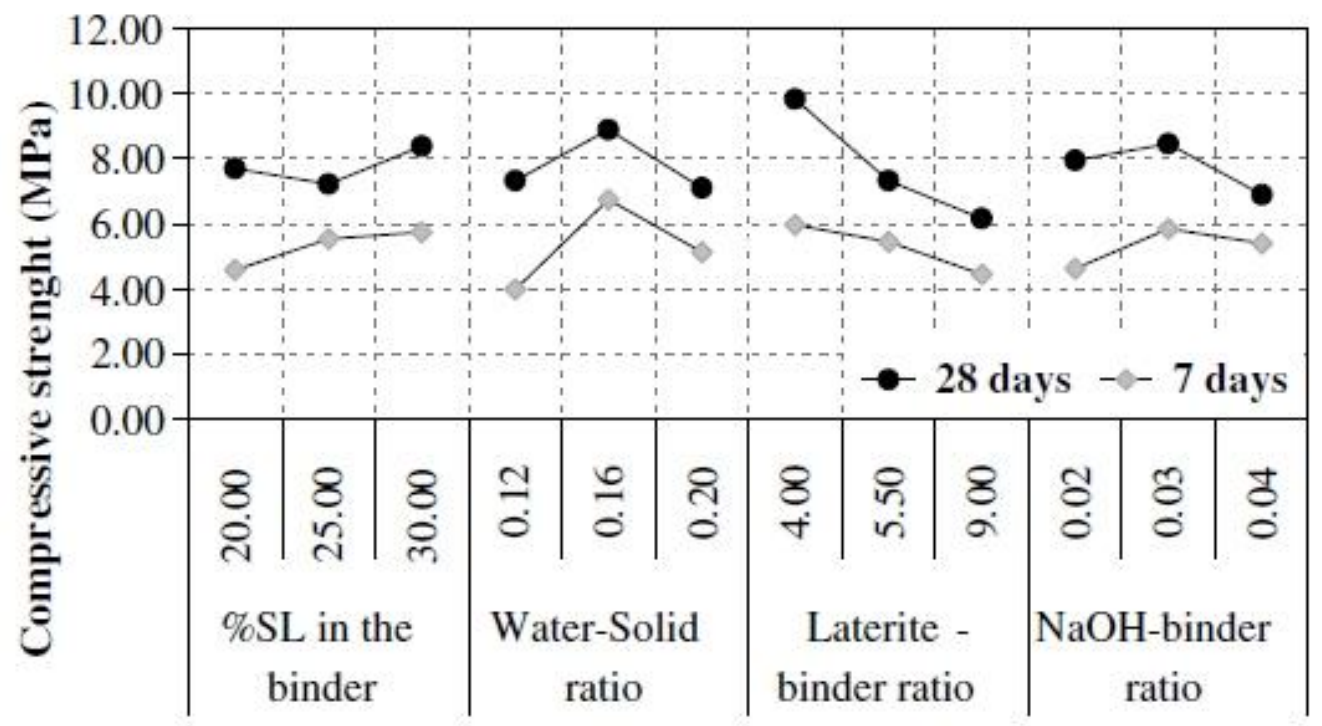

Factors \& modalities 
Figure 2. The average effect of factors (\% slaked lime in the binder, the ratios of water:solid, laterite:binder and $\mathrm{NaOH}$ :binder) on the water absorption of lateritic soil (adapted from [3]).

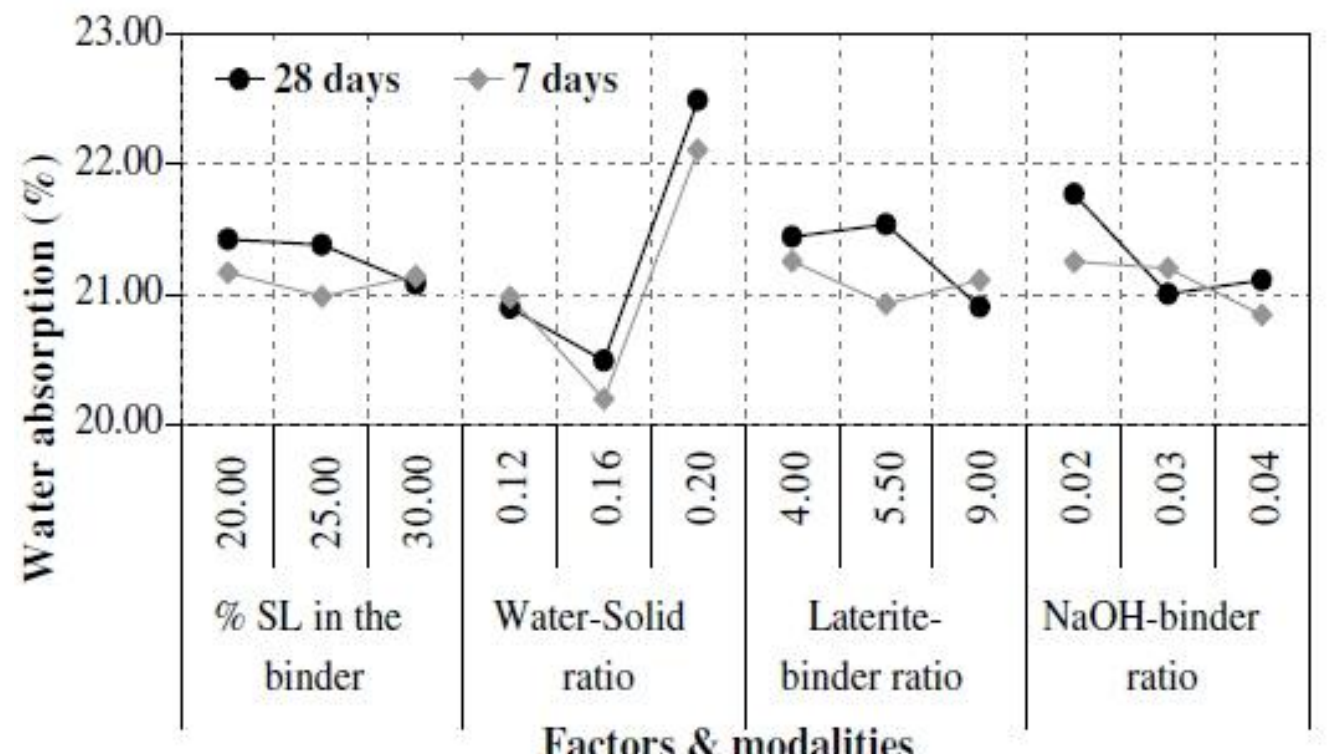

Figure 3. The average effect of factors (\% slaked lime in the binder, the ratios of water:solid, laterite:binder and $\mathrm{NaOH}$ :binder) on apparent density of lateritic soil (adapted from [3]).

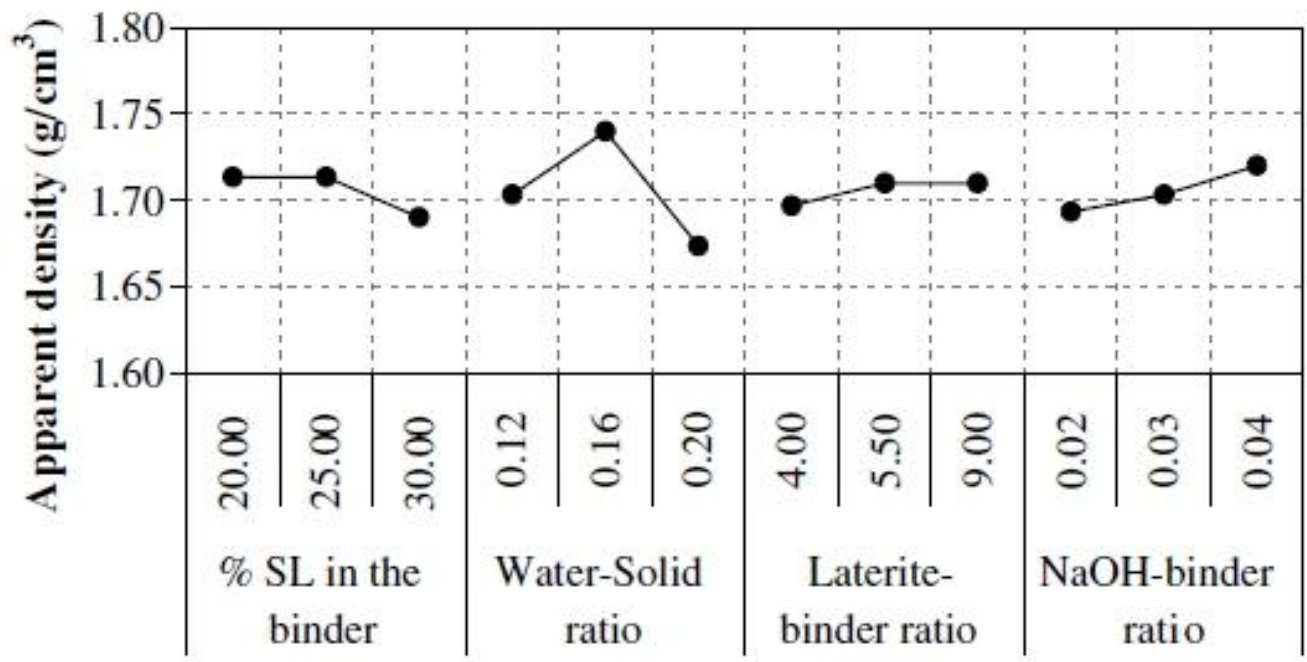

Factors \& modalities

The compressive strength above $2 \mathrm{MPa}$ qualified these products to be used for some building applications according to the Cameroon and ORAN ("Organisation Régionale Africaine de Normalisation” in English African Regional Organization for Standardization) standards on CEB. Despite the availability of these data, the production of CEB in Cameroon remains artisanal, with manual or automatic presses having a daily capacity range from 500 to 1500 blocks of $29 \times 14 \times 10 \mathrm{~cm}$ (length $\times$ wide $\times$ height). MIPROMALO is involved in the promotion of the production technology and in the renting of production equipment. When the soil is stabilized between $4-6 \%$ of cement, the 
cost of one stabilized CEB is around 85 Fcfa (about USD 0.17). Comparative studies made between $\mathrm{CEB}$ and cement concrete constructions in Cameroon have shown that CEB allows a reduction of 10-20\% of the global cost of houses depending on the implementation. This cost can be further reduced if the production is industrialized. The promotion of CEB production in Cameroon is facilitated by the Cameroonian standards existing for this product. These standards stand as a useful gateway for public or private construction contracts and are used by technicians to improve the quality of constructions.

C. Boutterin and J. Davidovits [13] studied the properties of improving lateritic soil through a low temperature geopolymeric process. The results of wet and dry compressive strength are presented in Figure 4.

Figure 4. Compressive strength in the presence of various quantities of alkaline reagent, at $85{ }^{\circ} \mathrm{C}$ and $450{ }^{\circ} \mathrm{C}$, after 24 hours of immersion in water followed by drying (adapted from [13]).

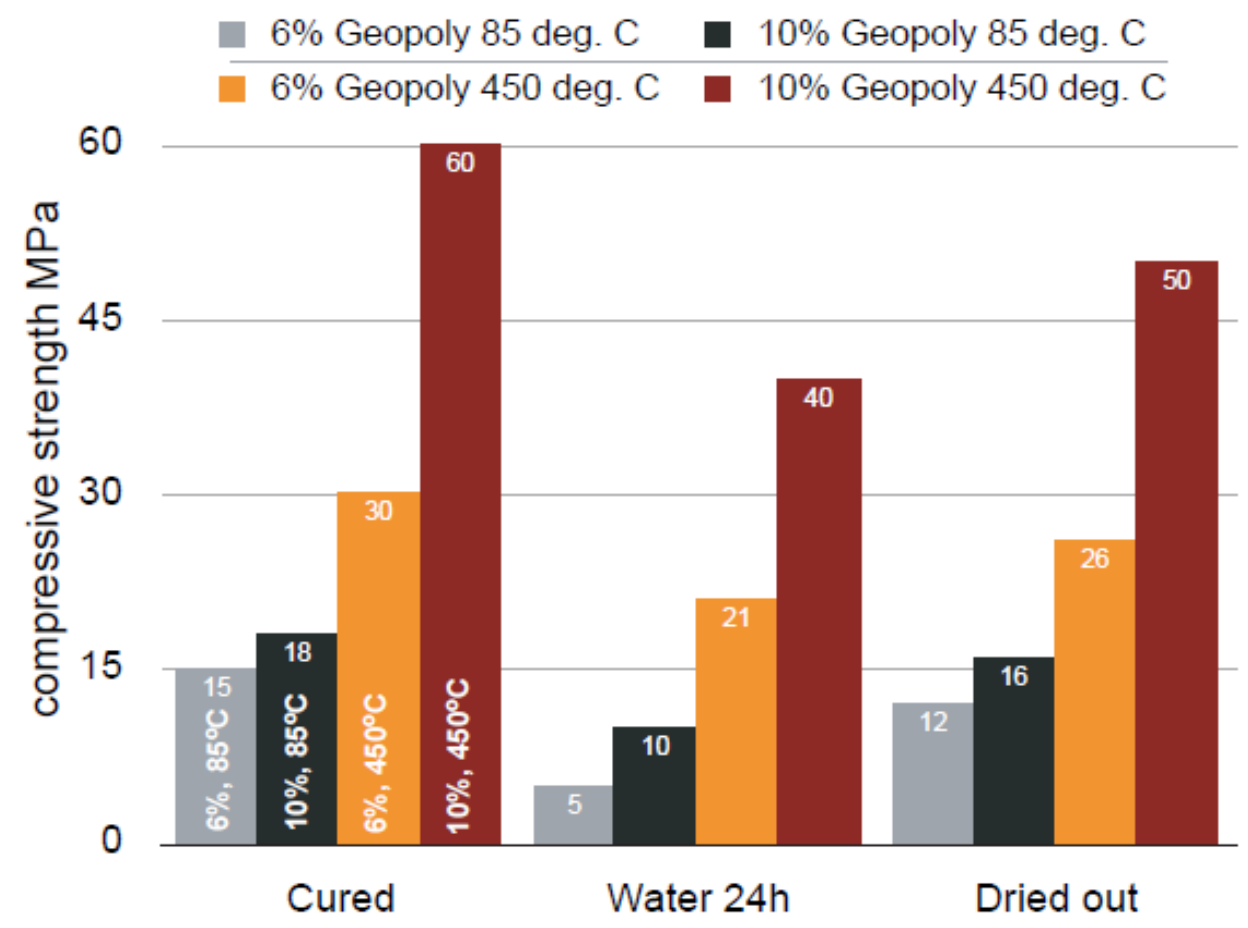

According to the quantity of alkaline reagent added to the argillaceous material, the geopolymeric cross-linking is more or less complete. For a lateritic soil, one can say that [13]:

(a) when alkaline reagent is added at $0.5-2 \%$ by weight, the soil is stabilized with a good behavior against water.

(b) with $2-5 \%$ alkaline reagent, blocks are water stable, with a compressive strength ranging from $4 \mathrm{MPa}$ to $6 \mathrm{MPa}$.

(c) with 5-10\% alkaline reagent, blocks are comparable to fired brick, with resistances ranging from 8-60 MPa.

These mechanical characteristics depend on the setting temperature. Each setting temperature yields a particular finished product. 
All materials manufactured with LTGS geopolymeric cross-linking preserve the quality of comfort specific to earth materials. This quality is neither disturbed by the medium temperature treatments $\left(85-450{ }^{\circ} \mathrm{C}\right)$, nor by the quantity of alkaline reagent added [13].

The production of geopolymeric stabilized based lateritic soils for construction purposes in Cameroon is still at the level of laboratory experimentation. Due to its environmentally friendly manufacturing process, studies are on-going to start artisanal or semi-industrial production.

Several other studies [15-21] have shown that there is potential to produce building materials presenting good civil engineering properties with earth or lateritic soils.

\section{Environmental Benefits and Lateritic Building Material Implementation}

The ecological and environmental benefits arising from the use of local building materials (especially those based on earth) are plentiful. It helps to reduce the amount of cement used in global building processes and consequently the amount of $\mathrm{CO}_{2}$ emitted and energy used for construction.

The largest growth in carbon emissions come from electricity generation, transport, industries and building operations [22] Cement (ordinary Portland cement) results from the calcinations of limestone (calcium carbonate) and silico-aluminous materials. The production of 1 ton of cement generates 0.55 tons of $\mathrm{CO}_{2}$ and needs the combustion of carbon-fuel into 0.40 tons of $\mathrm{CO}_{2}$ [23]. The world's cement-carbon-dioxide was evaluated at 1 and 1.8 billion tons in 1988 and 2000, respectively. Considering the trend observed in the cement market and industry, these $\mathrm{CO}_{2}$ emissions are expected to reach 3.5 billion tons by the year 2015 [14]. The reduction of cement consumption through the use of more ecologically-friendly building materials such as earthen products (CEB, adobe or cut laterites) is thus an ideal way to protect our environment through the reduction of energy consumption and $\mathrm{CO}_{2}$ emissions. The reduction of $\mathrm{CO}_{2}$ is of upmost importance as this harmful gas contributes to global warming through greenhouse effect.

The thermal insulation and thermal mass properties of building materials have been proven to significantly affect the amount of energy required for heating or cooling and, consequently, the total amount of electricity used in residential houses [22]. With its high density and valuable thermal inertia qualities, earth walls allow the storage of solar heat during the day and its slow release during the night, thus contributing to indoor comfort and reducing electricity consumption. In addition, earth walls remarkably regulate the humidity of indoor air due to their permeability to water vapor. Their production is generally in situ with no emission of greenhouse gases and without using a high amount of energy. These materials are ideal for the promotion of sustainable architecture (architecture designing windows and doors while taking into account the daily movement of the sun to create a comfortable climate in the house without recourse to expensive air conditioning).

However, despite all these ecological advantages and although earth has been one of the first building materials, some reticence still exists for earth building constructions. Indeed, earth has often been regarded as a building material for the poor, who find in it an ideal material for an inexpensive establishment. From cause to effect, poverty in means induces poverty in implementation; the quality of buildings depends on the budgets given. The choice of the earth is mostly dictated by financial means, as investments are reduced to a minimum. Consequently, the feeling of living refers to a paradoxical discomfort compared with traditional earth building suitable to context and climate. 
Building with earth without the required know-how and without regular maintenance undoubtedly led to the bad image that some people place on earthen structures today. However, this construction technique has been proven empirically, technically and scientifically. It has educational resources, which can be taught or valued as do all other materials [24]. Implementing earth (adobe, CEB, cutting lateritic) for the realization of decent housing should be made by respecting the specific nature of the material. The architectural beauty of earthen construction is realized in several countries through the world (Canada, France, the United States, etc.), and those in Cameroon by MIPROMALO, the Polytechnic national high school of Yaounde, the "Centre de Promotion des Artisans de Bafoussam" (CEPAB) and the Mutual for Property Landowner (MUPROF) are evidence of the potential of this material. Figures $(5,6,7 \mathrm{a}$ and $7 \mathrm{~b})$ below show photos of the degree of contrast that exists in the realization of earthen structures depending on how the materials are produced and implemented.

The discomfort associated with earth construction is therefore not inherent to the material, but with how it is used. However, a certain amount of money is required to ensure a comfortable standard of living. Its availability, like other local building materials, may also contribute to the socio-economic development of localities where these materials are used by reducing the amount of exported materials for building realizations.

Figure 5. Two photos of poorly constructed lateritic adobe houses in Cameroon.
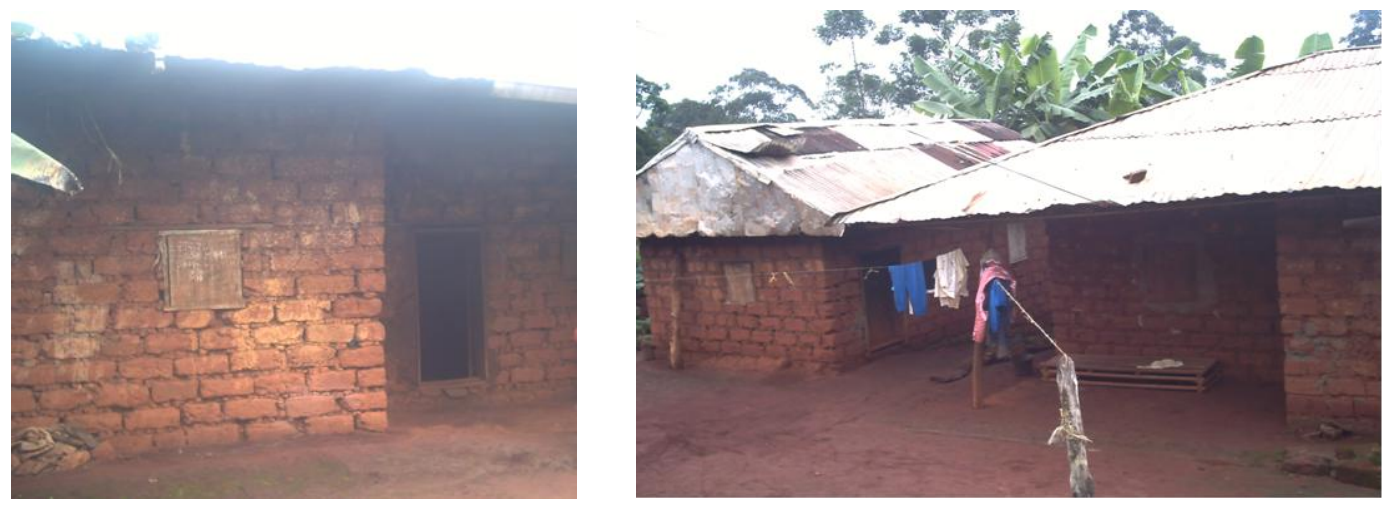

Figure 6. Two photos of classrooms with stone and Compressed Earth Blocks (CEB) with good implementation: MIPROMALO's realization, Cameroon.
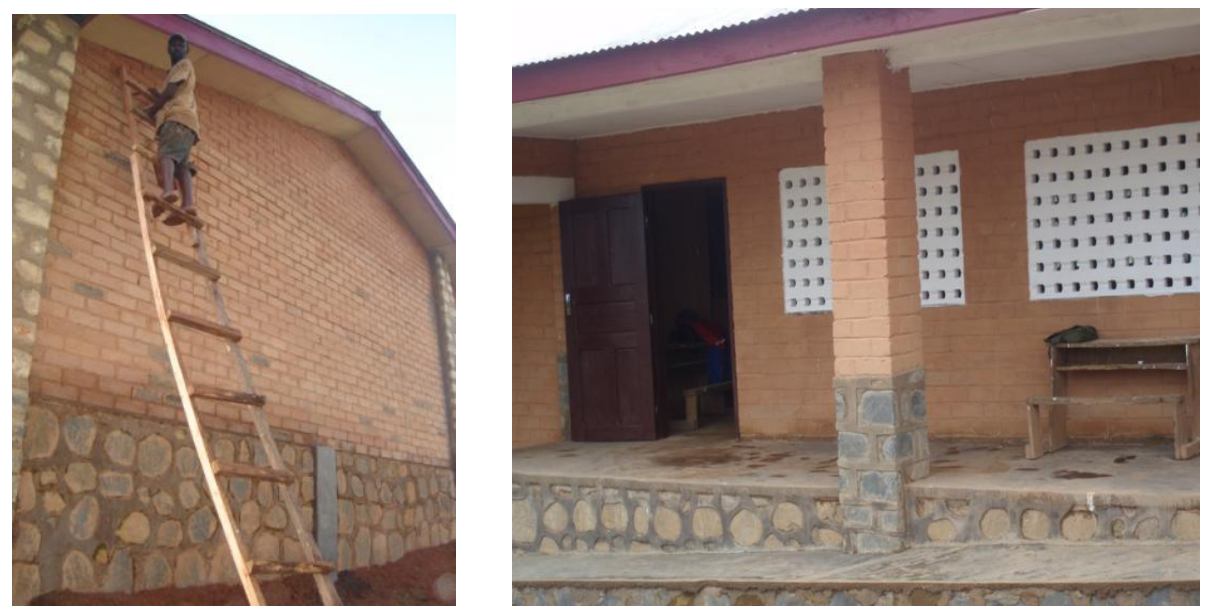
Figure 7. (a) CEB construction in Cameroon; and (b) Adobe construction in the USA.
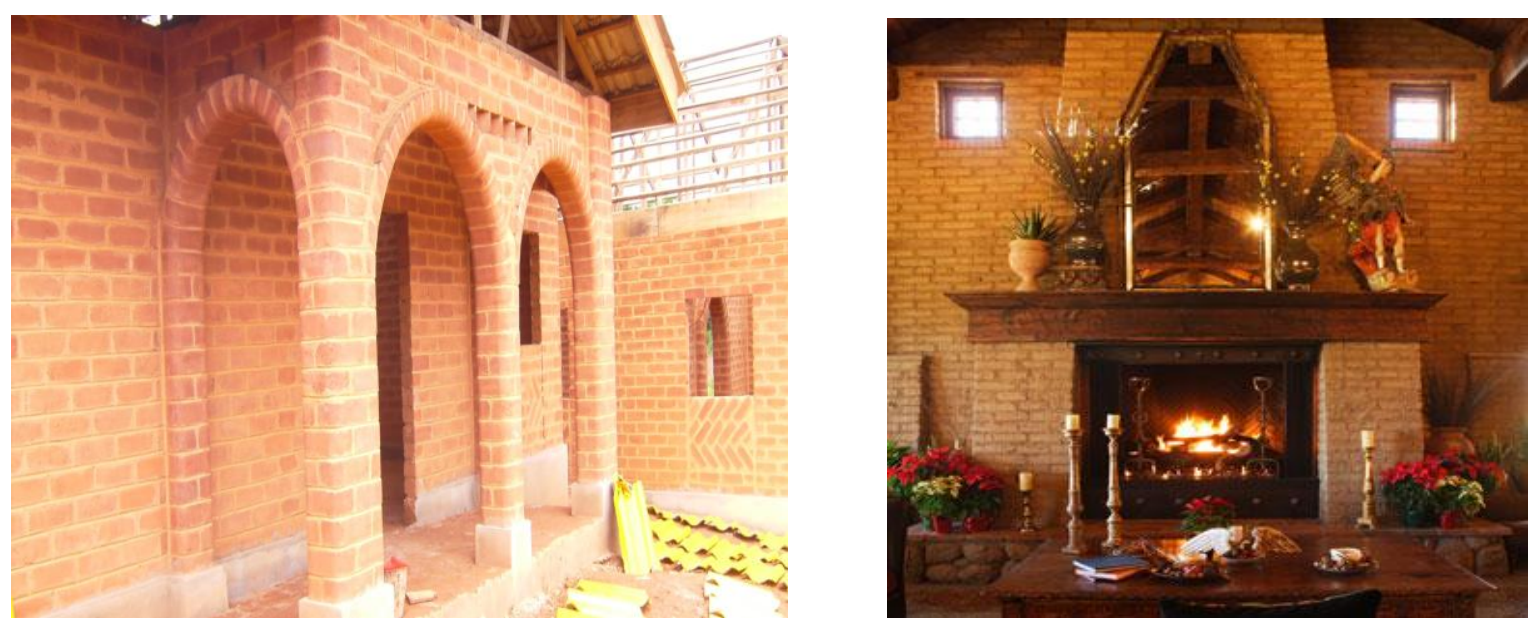

\section{Conclusions}

Lateritic soils are widely available in Africa and can be used to manufacture building material with good civil engineering properties through various ways.

These materials can be used to contribute to solving the problem of affordable housing if African governments put good policies into place, especially by encouraging research on local materials and by implementing efficient training programs on the use of earth-based construction.

By using local technology, local employment and local materials, one is working on the local currency, which allows much higher output levels from a limited budget. In addition, the results will be such that these homes could be maintained and repaired using local expertise and local materials. With the technology and materials available, it will be easier to solve the affordable housing issue in Africa.

\section{References}

1. Maignien, R. Review of Research on Laterite, Natural Resource Research IV; UNESCO: Paris, France, 1966; p. 148.

2. Zangato, E. Variantes architecturales des Tazunu du Nord-Ouest de la Republique Centrafricaine et evolution chrono-culturelle regionale. J. des Afri. 1995, 65, 125-143.

3. Billong, N.; Melo, U.C.; Louvet, F.; Njopwouo D. Properties of compressed lateritic soil stabilized with a burnt clay lime binder: Effect of mixture components. Construct. Build. Mater. 2009, 23, 2357-2360.

4. Podwojewski P et Bourdon E. Le processus d'induration des oxydisols goethitiques sur peridotites en Nouvelle-Caledonie: Unmode particulier d'induration de type plinthite. C.R. Acad. Sci. 1996, 322, 453-459.

5. Ola, S.A. The potentials of lime stabilazation of lateritic soils. Eng. Geol. 1977, 11, 305-317.

6. Mbumbia, L.; de Wilmarsa, A.M.; Tirlocq, J. Performance characteristics of lateritic soil bricks fired at low temperatures: A case study of Cameroon. Construct. Build. Mater. 2000, 14, 121-131. 
7. Houben, H.; Guillaud, H. Earth Construction: A Comprehensive Guide; Intermediate Technology Publications: London, UK, 1994; p. 73.

8. Stulz, R.; Mukerji, K. Appropriate Building Materials, Catalogue of Potential Solution, 3rd ed.; SKAT: St. Gallen, Switzerland, 1993; p. 29.

9. Tremblay, H. Amelioration Mecanique et Prediction de Compressibilite des Sols Fins du Quebec; Ph.D. Thesis; University Laval: Montreal, QC, Canada, 1998.

10. Billong, N.; Melo, C.; Ndikontar, M.K. Effet du Trona sur les Proprietes Hydrauliques d'un Ciment Portland Compose. Silicate Industriel 2008, 73, 17-23.

11. Kerali, G. Durability Of Compressed and Cement-Stabilised Building Blocks; Ph.D. Thesis; School of Engineering, University of Warwick: Warwich, UK, 2001.

12. Davidovits, J. Geopolymers of the first generation: Siliface-process, geopolymer. In Proceedings of the First European Conference on Soft Mineralurgy, Compiegne, France, 1-3 June 1988; Geopolymer Institute: Compiegne, France, 1988; pp. 49-67.

13. Boutterin, J.D. Reticulation Geopolymerique (LTGS) et Materiaux de Construction. Geopolymere 2003, 1, 79-88.

14. Davidovits, J. Geopolymer Chemistry and Application, 2nd ed.; Geopolymer Institute: Saint-Quentin, France, 2008; p. 586.

15. Basha, E.A.; Hashim, R.; Mahmud, H.; Muntohar, A.S. Stabilisation of residual soil with rice husk ash and cement. Construct. Build. Mater. 2005, 19, 448-453.

16. Lasisi, F.; Osunade, J.A. Effect of grain size on the strength of cubes made from Lateritic soils. Build. Environ. 1984, 19, 55-58.

17. Hossain, K.M.A.; Lachemi, M.; Easa, S. Stabilized soils for construction applications incorporating natural resources of Papua New Guinea. Res. Cons. Rec. 2007, 51, 711-731.

18. Rahman, M.D. The potentials of some stabilizers for the use of lateritic soil in construction. Build. Environ. 1986, 21, 57-61.

19. Anifowose, Y. Effect of bentonite on the strength of fired lateritic soil blocks. Construct. Build. Mater. 1996, 10, 457-459.

20. Millogo, Y.; Hajjaji, M.; Ouedraogo, R.; Gomina, M. Cement-lateritic gravels mixtures: Microstructure and strength characteristics. Construct. Build. Mater. 2008, 22, 2078-2086.

21. Attoh-Okine, B. Stabilizing effect of locally produced lime on selected lateritic soils. Construct. Build. Mater. 1990, 4, 86-91.

22. Radhi, H. Evaluating the potential impact of global warming on the UAE residential buildings-A contribution to reduce the $\mathrm{CO}_{2}$ emissions. Build. Environ. 2009, 44, 2451-2462.

23. Davidovits, J. Geopolymer: Inorganic polymeric new materials. J. Therm. Anal. 1991, 37, 1633-1656.

24. Nko'O, C.B. Etudes Prospectives Pour le Developpement d'un Habitat de Qualite en Adobe a Koudougou, Burkina Faso; Memoire du DAS-AT Ecole Nationale Superieure d'Architecture de Grenoble: Grenoble, France, 2006.

(C) 2011 by the authors; licensee MDPI, Basel, Switzerland. This article is an open access article distributed under the terms and conditions of the Creative Commons Attribution license (http://creativecommons.org/licenses/by/3.0/). 